\title{
Gender Equality Provided by Active Action in Recruitment and Selection Process
}

\author{
Klára Tatár-Kiss
}

ELTE Doctoral School of Sociology

\section{THE AIM OF THE PAPER}

Despite all the efforts in relation to hiring women to workplaces, parity has not yet been achieved, and the gap between women and men is even wider when leadership roles are considered. Organizations are gendered, the human resource practices are outdated and are still structured around the ideal, male worker. The main objective of this paper is to critically review the recruitment and selection process (RSP) and provide active actions as practical recommendations, which will enable organisations to hire women into the workplaces.

\section{METHODOLOGY}

This research is an empirical study of large multinational organizations, identifying the key human resource policy intervention points in the RSP.

\section{MOST IMPORTANT RESULTS}

The outcome of the critical review is that the traditional RSP needs to be transformed and only this transformation - applying positive actions - will enable organisations to achieve gender equality at the workplace. The novelty of this paper is the empirical research of global organizations, based on which, the key intervention points of RSM were identified. The following active actions are proposed: embed employer branding and early talent attraction into the recruitment process; provide transparency of salary bands; apply of female quotas; use structured interviews; run diverse interview panels; and use explicit comparator method.

Keywords: gender equality, recruitment and selection, active actions

DOI: 10.15170/MM.2021.55.03.04 


\section{INTRODUCTION}

Gender equality, in the process of building a more inclusive society and economy continues to be a global mandate in the $21^{\text {st }}$ century. Global Gender Gap reports have been tracking the progress over the last 14 years and analysed gender parity across education, health, political power, and economic participation. Against all the efforts and improvements, there is still an average 31,4\% gender gap globally. In terms of labour force participation still only $55 \%$ of adult women are in the labour market versus $78 \%$ of adult men and moreover, the report confirmed an over $40 \%$ of wage gap and over $50 \%$ of income gap (Global Gender Gap Report 2020, 2019).

Organizations are responsible for addressing gender inequality and they have the potential to accelerate the progress. At first glance hiring women to workplaces as an objective seems concise and clear, however, as Human Resource Management (HRM) is traditionally a male based discipline and was built around the ideal male worker (Ternovszky 2013), the RSP will need to be transformed into an inclusive one, enabling women to have equal participation to men.

\section{LITERATURE REVIEW}

Acker argues that organizations are gendered, and that gender cannot be separated from its social contexts. Organizations are workplaces where gender, race and class are intertwined and these relationships are reproduced through organizational practices and policies (Acker 1990). The gendered norms are based on the traditional division of labour, therefore this is the main ruling principle in defining who gets hired, promoted and rewarded in a workplace (Acker 2007). Organizations are constantly "doing gender" by creating gender related identities in their policies and language usage (Nagy 2017). If organizations have the ability to "do gender" they also must have the capability to "undo" it, which requires a rigorous and critical review of its gendered internal practices. Critical thinking is required to change these outdated practices, which are serving to keep the men in the status quo allowing them to keep male privileges. Bob Pease argues that for every oppressed group there is a privileged one. Dominant groups are allowed to reinforce their dominance and exercise their superior rights above the oppressed ones. Pease urges the white, western, elitist men to undo their patriarchal privileges and considers this to be the individual's moral obligation (Pease, 2010).
Management practices and particularly HRM are established to cater for the ideal worker i.e. for the white, middle-class man. Historically, these policies and practices were developed based on the masculine dominance, which on the one hand prevents alternative conceptualization and on the other hand hinders equality. These masculine HRM practices are "putting the field at risk of becoming co-opted into hegemonic practices that are preventing it from fulfilling its goal of humanistically facilitating development and change" (Bierema 2009, 91). Ironically, the human resource professional has been feminized -as the interview subject gender ratio indicates in this research -13 female out of 16 HR professionals -, women as human resource professionals still maintain the traditional, masculine HRM practices.

The traditional HRM concepts consider equal opportunities as part of the HRM (Armstrong \& Taylor, 2014, Sisson, 1994) but Dickens disagrees with this notion and argues that this statement is a "rhetoric rather than reality" (Dickens 1998, 23). There is a current scholarly emerging trend of Critical Management Studies (CMS), which is gaining more popularity internationally and in Hungary. CMS aims to challenge the existing systems and urges to find alternatives (Alvesson et al. 2009). Hidegh et al emphasizes that CMS is even more important in Hungary than in Western Europe. They state that during the two decades of capitalism the local decision making elite was too occupied by achieving economic growth, while completely ignored the emerging social trends in Western Europe such as inequality or strengthening patriarchy (Hidegh et al. 2014).

HRM offers a wide range of policies and procedures for CMS. Keenoy views HRM as a discursive cultural artifact, using Foucault's term of "discursive formations" to critically assess mainstream HRM literature. As a conclusion, Keenoy views HRM as a governance framework, HRM practices "collectively, constitute the "disciplinary practices" regulating social behaviour at work. Such "powerknowledge" mechanisms play a discursive role in constituting employee subjectivities and ensuring that employee performance(s) can be "managed." (Keenoy 2009, 467). The purpose of the mainstream HRM is to serve the neoliberal objectives of mangers (Alvesson et al. 2009). Other researches point out the lack of feminist critique in human resource development and considers this alarming (Bierma 1998, Rocco et al. 2018) CMS in HRMS started to gain significance in Hungarian research as well. Hidegh carried out the Habermasian analysis of soft HRM and concluded that in modern socie- 
ties HRM works as a colonizing power, which then interferes with the reproduction processes of the lifeworld as well as the workplace (Hidegh 2018).

Women have been entering the labour market gradually meaning that the workforce composition has been changing, yet HRM practices are still decades old and are built for the ideal male worker or "organizational man" (Acker 1990, 145) and therefore these practices maintain the inequalities between women and men at workplaces (Guy \& Spice 2009). This outdated masculine norm leads to several disadvantages for women manifested in areas like career development, compensation, work-life balance and penalizes motherhood. HRM practices and policies - such as RSP, learning and development, talent management, compensation and benefit - can attribute to the workplace inequality (Stamarski \& Son Hing, 2015). Particularly, RSP can be the cause of gender disparity at the workplaces (El Arnaout et al. 2019).

Several competing theories co-exist about gender inequality and they take a different view about the root cause of the problem. As an example, Gender Stratification theory considers that the discriminatory approach of the recruiters and hiring managers is behind the workplace gender inequality. According to this theory, women have less capability and lower commitment to work compared to men (El Arnaout et al. 2019). RSP is a key HRM process, which - in theory -supports hiring women to the organization as well as to leadership roles. In reality, even if women are hired, they are typically hired into low paid positions while men are chosen for high paid and leadership roles (Fernández \& Mors 2008). It was proven by empirical research that the gendered RSP is responsible for maintaining the inequal status quo of women and men (Lee Cooke \& Xiao 2014). As a starting point, women will need to be hired to the right roles and only then can other HRM processes (talent management, career and advancement, learning and development, retention policies) ensure that there is gender balance at all levels of the organization.

For this empirical research Armstrong's RSP was applied as the main framework and a critical review of this process was conducted. Armstrong's HRM handbook was initially published in 1977 but even today many educational faculties teaching human resource management use the $13^{\text {th }}$ edition (Armstrong \& Taylor 2014). The paper also provides active actions, practical recommendations in the RSP to address gender inequalities.

It is crucial to note the difference between positive discrimination and positive action (Gregory-Smith 2018). Positive discrimination - which is generally unlawful unless defined in legislation differently- in recruitment means hiring someone for having certain minority characteristics and not because the person is the most suitable candidate for the role. On the other hand, positive action in recruitment comes into place when two candidates have exactly the same skills, they are equally fit for the job, and then, the company can decide to hire the one from the underrepresented group.

The researched organisations geographically operate in the European Union and United Kingdom, therefore it is also important to briefly mention the normative role of the $\mathrm{EU}$ in gender equality. The Directive 2006/54/EC (Gender Recast Directive) of the European Parliament and the Council (July 2006) regulates the implementation of the principle of equal opportunities and equal treatment of men and women in matters of employment and occupation.

\section{METHODOLOGY}

The main research of the paper is as to what extent the RSP increases women's employment in global organisations and what active actions are required in the process in order to achieve gender equality at the workplace. The interview topics were defined along with Armstrong's recruitment cycle.

The research method is qualitative, structured interviews providing the base of the main methodology, which were conducted with 19 interview subjects. While choosing the companies and interview subjects, snowballing sampling was applied and 19 interviews were conducted. The appendix contains the details. In terms of the company demographics three large multinational corporations were researched, which have global presence and operate in a diverse environment, having their headquarters either in the United States or in the United Kingdom. These companies operate in various sectors: retail, financial services, apparel and in total have an approximate headcount of 700,000 employees.

\section{FINDINGS}

Although the RSPs somewhat differ in the three researched organizations, there are significant similarities in those practices.

\section{Step minus 1 - Early talent attractions}

Based on the results it can be concluded that all the organizations realized the need to engage with their future employees as early as possible. This 
in practice meant attracting university students through various events like job fair, career fair, university collaboration, summer internship and graduate internship programs and various scholarship programs. As one of the researched organizations operates in the highly masculine financial services industry, there were special programs in place to address the low woman representation of the STEM areas. This meant the leadership and sponsorship of programs like the "Girls in Technology". The organization did not only promote the program, but also provided female role models to the university students to motivate young women for breaking the barriers. Inspirational speeches and role modelling have been identified as core active actions to address the gender gap in the STEM subjects. One of the organizations have even gone one step further and understood that to have a sufficient woman pipeline at the workplace, it is already too late to address the gender gap issue at university level. Realizing the importance of the timing factor, this company has reached out to secondary schools, invited young female students to their workplace, and also engaged with a non-profit organization with the objective of reaching out to students early at their studies. Reaching out to female students as early as high school can be critical to mitigate the risk of occupational segregation, which is already clearly visible in tertiary education.

\section{Step 0. - Employer branding as a stra- tegic pillar}

All the interview subjects confirmed that their companies apply employer branding to promote inclusive culture. Although all the organizations were well -known and owned popular brands, yet, they considered that employer branding is pivotal to build a sufficient talent pipeline. The research confirmed that before starting any recruitment, branding will first need to be developed and that company brands are no longer sufficient to attract talents and employer branding has become pivotal.

"The war for talent is over and talent won. This is a candidate driven market and we must adjust our recruitment strategy. ... People will no longer knock at our door just because we are who we are. We have to be the choice of the employee and use employer branding to attract the right talent." Interview subject 3.

The following active actions were identified in the research as part of the employer branding strategy to attract more women candidates: statements on diversity (e.g. minorities/females/veterans/ disabled); using visual images to promote women at workplace; adding award logos to recruitment ads (e.g. best working place for moms, family friendly logo); listing benefits in the offerings (e.g. paid parental leave, flexible working arrangements, work-life initiatives). There is a very clear employer branding strategy in all the organizations with a fundamental focus on diversity and inclusion. Employer branding concentrating on attracting women can be considered as a best practice with the expected outcome of developing a robust female pipeline for future hiring. The diversity and inclusion ratings of these companies are at the upper end of the scale on Glassdoor: 4.1, 3,9 and 3,9 out of the maximum 5 score. Employee testimonials at Glassdoor include statements like:

Figure 1. Employee testimonials at Glassdoor about the companies' diversity practices

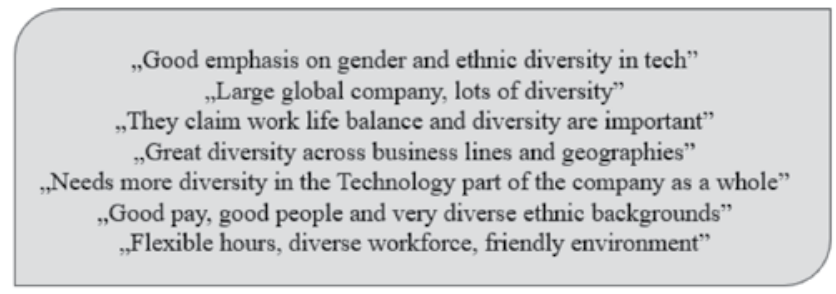

Source: own analysis based on Glassdoor portal 


\section{Step 1. - Defining requirements - buil- ding role profile}

All companies had a unique standard template in terms of role profiles, which was used when a vacancy occurred, or a new role was created. These templates included key information about the role such as: purpose, context, impact, roles and responsibilities, key competencies and required skills and experiences (KSA: knowledge, skills and abilities), education. In one of the organizations these role profiles were driven by global standards while in the other two only the format was defined by the centrum headquarter and the content was determined locally. All the three organizations used English as their internal business language therefore this was the language of the role profiles too. Using English language globally is particularly useful as the professions are not linked to gender unlike in some other languages (lehrer-lehrerin, serveur-serveuse, tanár-tanárnő).

\section{Step-2. Attracting candidates}

All the companies had the policy of transparency, which meant that any job vacancy needed to be posted internally. As above, English as a language will not link a profession to gender, yet this does not mean that the words are not carrying gender related connotations. The linguistic gender-decoding is based on the social expectation of what men and women are like (e.g. bossy is a woman, great boss is a man) and only this deep level of analysis can unfold the hidden gendered codes used in the job advertisement. In practice, one of the organizations has already realized the importance of language and started to gender decode all the job advertisements, however, at this stage there is no empirical evidence to prove the effectiveness of this practice on the hiring ratio of women.

The interviews highlighted another potential active action as best practice to address workplace inequalities. In all companies but only in certain countries salary bands were included in the job advertisement.

"Showing salary bands enables women to know what they don't know that they don't know." Interview subject 12.

The willingness to talk about salaries and compensation packages is driven culturally. In some countries it is more accepted, therefore job advertisements are more transparent and include salary bands (e.g. United Kingdom), while in other countries the market practice is to even include a confi- dentiality clause in relation to salaries (e.g. Hungary).

"Displaying our salaries in a paper would be a disaster! Firstly, we will become an easy target for competitors, secondly, what do I tell my employees who are below the minimum threshold of the band? This is a nonsense. Would mean a revolution. And turnover." - Interview subject 16.

Transparency about salary ranges might seem to be a low hanging fruit to foster the culture of gender equality, yet some countries culturally might not be ready to embark on this journey. Nevertheless, transparency is an ethical and moral consideration of senior leaders in the organizations. As a remark - although gender pay gap is not in the scope of this research- full transparency of compensation is one of the elements in closing the raw gender pay gap.

In terms of the sourcing methodology, all the companies had a relatively complex source mix composition, including methods such as: assessment centre, internal recruitment, online postings, social media coverage, agency or head-hunter/executive consultant usage and employee referral. In terms of the methodology there were no differences based on gender.

\section{Step-3. Sifting application}

In all the companies there is a software support to screen the incoming curriculums, however the main point of control is the recruiter. It is the recruiter's responsibility to pre-select the candidates and to present the short list to the relevant hiring function.

None of the companies have considered requesting blind $C V s$, which is a curriculum not including the applicant's personal data such as age, gender, ethnicity.

Female quota in recruitment has been identified as a universal active action during the research. All the interview subjects- across all companies and geographies - confirmed that there is a female quota in the hiring practice. In some of the organizations it is a "highly" recommended practice while in another one it is a "must have". On the one hand, this is part of the inclusive culture aspiration of the studied global multinational corporations but on the other hand this is also a regulatory expectation as all three companies are listed companies. The interviews highlighted the "comply or explain" philosophy, which means that the recruiters and hiring managers will need to comply with the female quota and should they fail, an explanation will need to be provided to senior leaders of the organization. While the first approach has a lighter enforcement 
on quotas, the latter one is more forceful. The forcefulness of the approach was criticized by one of the interview participants:

"It is really cool that they stop now the recruitment process. While I am measured on time to fill, I need to stand still until a woman is found. Should I clone one?". - Interview subject 4.

\section{Step 4. Interviewing}

The common preferred option for interviews in these organizations were the structured, competency based interviews, however 7 of the interviewed subjects mentioned that they occasionally use unstructured interviews, especially when managers are not equipped with the necessary technical knowledge to run the competency based interviews. The use of unstructured interview methodology might seem to be convenient, however, the interviews unrevealed several drawbacks such as "impossible to compare candidates" and "too subjective way". There is a clear disadvantage of conducting unstructured interviews, as the predictive validity is relatively low. The research confirmed the preference for running competency based structured interviews. Other than overcoming the barriers of the subjective nature of the unstructured interviews, competency based methodology has another great advantage, namely, that the method allows to conduct the assessment based on the global/regional leadership standard competencies i.e. based on identical selection measures all across the organization. This can give more space for a less subjective assessment, as the methodology excludes the preferences of the interviewers.

In terms of who is interviewing, the companies applied different approaches. This was the most controversial element of the research and companies had several variations. Two of the researched organizations did not have any policy governing interview participants. In these companies, interviews were often done in a 1:1 manner. This meant that gender did not have a role to play considering the interviewer's character. The third company had a more rigorous approach and opted for diverse interview panels. This practice meant that in every interview panel there had to be a woman participating. The logic behind is based on the concept of demographic similarities i.e. a woman in the interview panel will prefer a candidate with similar demographic features (Tsui et al. 1992). As the empirical results have shown, there are very different concepts of running the interviews. This is also probably the reflection of the ongoing academic debate around how best to run interviews from a diversity perspective. One school of thoughts argues that only diverse interview panels can be efficient to hire more women as female panellists will reduce male unconscious bias (McCarthy et al. 2010, Ternovszky 2013) while another school of thoughts disagrees with this and argues that such a forced female panel participation will lower the importance of the competencies required by the role (McFarland et al. 2004). Furthermore, some other empirical researches argue that the interview panel is not an efficient way of recruiting (Bohnet 2016, Dixon et al. 2002). This is certainly an area, which requires further analysis, involving more companies and assessing recruitment outcomes.

\section{Step 5. - Testing}

None of the researched organizations used testing as a standard recruitment tool. Testing (personality, ability or aptitude) was mentioned to be applied in more junior recruitments and typically in assessment centres. Cost and return on investment were the major concerns for using tests. Even if tests were used occasionally, none of the interviews confirmed any specific gender related aspect of those.

\section{Step 6. - Assessing candidates}

All companies had some sort of "wash up" meetings after the interviews were completed by all stakeholders. The research pointed out some of the disadvantages of such a common, team based decision making process:

"Should I fight with him (CEO) if he believes that is the best person to fit?" Interview subject 2.

"Honestly, there is no point of endless arguments, it is a waste of time" - Interview subject 11.

"I always go with the flow."- Interview subject 3.

These quotes point out the inefficiencies of the large group, unstructured evaluation processes. This is an interesting finding, especially that the lack of honest conversations and evaluations can hinder the gender equality objective. It was a surprising result as all the three global organizations are thriving for best in class human resource practices, yet none of them have considered the most recent academic results on effective selection. Explicit comparator methodology - when two candidates are assessed and compared to one another - were proven to be successful in overcoming stereotyping assessments. This is definitely an active action to be taken for further consideration. 


\section{Step 7-8. - Obtaining references and Checking applications}

Armstrong \& Taylor considers referencing and checking applications as two separate steps of the RSP (Armstrong \& Taylor, 2014), however the empirical research of the companies concluded that these steps in practice are merged. As the research highlighted, references were used on an ad hoc base in two of the companies, while one had a standard background screening process. This is due to the complex employment legal background of the subsidiaries. The background screening process had nothing specific related to gender, it was identified to be a standard, regulatory driven process.

\section{Step 9. - Offering employment}

Standard offer letter templates were used in all the organizations. In all the offer letter templates there was a specific section on financial and non-financial benefits, which listed all the available benefit items and specifically referred to work/life balance programs, parenting benefits, childcare benefits, flexible working arrangements. Listing a wide range of benefits can be a competitive advantage to the company and can attract more diverse - female - talents as well. One of the interview subjects said:

"Showing inclusive benefits in the offer letter is like our shop window. We want to let the candidate know how inclusive we are, and the offer letter has the objective to do so." - Interview subject 3 .

The wide range of available benefits indicate that all the studied companies consider diversity as a strategy and inclusive leadership as a key driving principle. However, the contradiction is, that although the companies declare having inclusive culture, none of them have yet achieved gender equality at all levels of the organisation. It is important to have a transparent benefit portfolio with a value proposition for female talents. Considering that care work at home is typically performed by women, flexible working arrangements, schooling benefits and family friendly programs can attract more women.

\section{Step 10. - Following up}

All the organizations had some sort of onboarding programs, new joiner programs with a typical length of 30 to 90 days. However, in all of these companies onboarding has fallen out of the scope of the RSP. While Armstrong (2014) considers the "following up" as the last point of the RSP, the empirical results show that onboarding is either owned by the direct manager or by another human resources function (typically HR Business Partner). The review of the onboarding practices did not indicate any specific intervention point for gender equality.

\section{CONCLUSIONS AND RECOM- MENDATIONS}

It was concluded that the RSP can be universal i.e. can be successfully applied across various companies and geographies. The studied global multinational companies not only had very similar recruitment and selection practices across their geographies but also had very similar practices in comparison to each other. The research concluded that the recruitment and selection practices need to go under transformation to enable effective hiring of women to the organizations, particularly to leadership roles.

Key intervention were identified and active actions were recommended. It is recommended to have two more initial stages added to the recruitment process. The first step is to have a clear focus and strategy on "early in career talent/employee/ women attraction", which in practice means the ways of engaging with young female students (high school) in order to influence their future studies and provide successful female career role models. The second step to be added is employer branding with a specific focus on women. Companies must be more visible and open to public about their initiatives about diversity, particularly women at the workplace. This will differentiate companies from one another and will also allow female workers to choose the best fitting company.

Gender decoding, the use of technology, can be a new tool to further explore, however in this research, its effectiveness in increasing women's hiring ratio was not proven.

There is another potential intervention to be added to the "attracting candidates' stage, which is to have transparency about salary bands. Depending on the local socio-cultural and legislative context, transparent and visible salary ranges can support equal pay and reduce the gender gap.

In the "sifting application" stage the female quota in the selection process has been proven to be effective. The research also uncovered the potential conflict between the speed of recruitment (time to hire) and the female quota, therefore when launching the quota, the full RSP key performance indicators should be reviewed. 
In terms of "interviewing" companies should invest into developing competency based structured interview tools and train all hiring managers. At the interview stage it is recommended to have diverse interview panels, including female participants.

In the "assessment stage" explicit comparator methodology is recommended as best practice.

Finally, at the offer letter stage companies should develop their documents to be relevant to female employees and do their best to promote the inclusive culture of the organization.

\section{LIMITATIONS AND FUTURE STUDIES}

The limitation of this paper is the number of the participating organizations therefore including more organizations across more diverse geographies can add to the robustness of this research. The usage of gender decoding tools in the RSP can be a future research area especially a longitudinal study could be carried out.

\section{REFERENCES}

Acker, J. (1990). HIERARCHIES, JOBS, BODIES: A Theory of Gendered Organizations. Gender \& Society, 4(2), 139-158. https://doi. $\mathrm{rg} / 10.1177 / 089124390004002002$

Acker, J. (2007). A társadalmi nem és a szervezet irányzat jövője, kapcsolódások és határvonalak. In B. Nagy (Ed.), Szervezet, menedzsment és nemek (pp. 13-30). Aula.

Alvesson, M., Bridgman, T., \& Willmott, H. (2009). The Oxford Handbook of Critical Management Studies. https://doi.org/10.1093/ fordhb/9780199237715.001.0001

Armstrong, M., \& Taylor, S. (2014). Armstrong's Handbook of Human Resource Management Practice (13th ed.). Kogan Page.

Bierema, L. (2009). Critiquing Human Resource Development's Dominant Masculine Rationality and Evaluating Its Impact. Human Resource Development Review, 8, 68-96. https://doi. org/10.1177/1534484308330020

Bierma, L. L. (1998). A Feminist Critique of Human Resource Development Research.

Bohnet, I. (2016). What Works- Gender Equality by Design. The Belknap Press of Harvard University Press.

Dickens, L. (1998). What HRM means for gender equality. Human Resource Management Journal, 8(1), 23-40. https://doi. org/10.1111/j.1748-8583.1998.tb00157.x

Dixon, M., Wang, S., Calvin, J., Dineen, B., \& Tomlinson, E. (2002). The Panel Interview: A Review of Empirical Research and Guidelines for Practice. Public Personnel
Management, 31(3), 397-428. https://doi. $\mathrm{rg} / 10.1177 / 009102600203100310$

El Arnaout, N., Chehab, R. F., Rafii, B., \& Alameddine, M. (2019). Gender equity in planning, development and management of human resources for health: A scoping review. Human Resources for Health, 17(1), 52. https://doi. org/10.1186/s12960-019-0391-3

Fernández, R. M., \& Mors, M. L. (2008). Competing for jobs: Labor queues and gender sorting in the hiring process. Social Science Research, 37 4, 1061-1080.

Global Gender Gap Report 2020. (2019). World Economic Forum. https://www.weforum.org/ reports/gender-gap-2020-report-100-years-payequality

Gregory-Smith, I. (2018). Positive Action Towards Gender Equality: Evidence from the Athena SWAN Charter in UK Medical Schools. British Journal of Industrial Relations, 56(3), 463-483. https://doi.org/10.1111/bjir.12252

Guy, M. E., \& Spice, S. (2009). Gender and workplace issues. In S. W. Hays, R. C. Kearney, \& J. D. Coggburn (Eds.), Public human resource management: Problems and prospect (5th ed., pp. 236-252). Pearson.

Hidegh, A. (2018). Az emberierőforrás-menedzsment habermasi kritikája. Replika, 77-96. https://doi.org/10.32564/106-107.5

Hidegh, A., Gelei, A., \& Primecz, H. (2014). Mi a baj a modern szervezetekkel? - Kritikai menedzsmentelméletek (What is the problem in modern organisations? - Critical Management Studies). Vezetéstudomány / Budapest Management Review, 45. https://doi.org/10.14267/ VEZTUD.2014.06.01 
Keenoy, T. (2009). Human Resource Management. In The Oxford Handbook of Critical Management Studies (pp. 454-472). https://doi. org/10.1093/fordhb/9780199595686.013.0022

Lee Cooke, F., \& Xiao, Y. (2014). Gender Roles and Organizational HR Practices: The Case of Women's Careers in Accountancy and Consultancy Firms in China. Human Resource Management, 53(1), 23-44. https://doi.org/10.1002/ hrm. 21566

McCarthy, J. M., Van Iddekinge, C. H., \& Campion, M. A. (2010). Are highly structured job interviews resistant to demographic similarity effects? Personnel Psychology, 63(2), 325-359. https://doi.org/10.1111/j.17446570.2010.01172.x

McFarland, L. A., Ryan, A. M., Sacco, J. M., \& Kriska, S. D. (2004). Examination of Structured Interview Ratings Across Time: The Effects of Applicant Race, Rater Race, and Panel Composition. Journal of Management, 30(4), 435-452. https://doi.org/10.1016/j.jm.2003.09.004

Nagy, B. (2017). Szervezet és nemek. In M. Kovács
(Ed.), TÁRSADALMI NEMEK: Elméleti megközelitések és kutatási eredmények (pp. 57-68).

Pease, B. (2010). Undoing Privilege. The University of Chicago Ptress Books.

Rocco, T., Munn, S. L., \& Collins, J. (2018). The critical turn in human resources development.

Sisson, K. (1994). Personnel management: A comprehensive guide to theory and practice in Britain.

Stamarski, C., \& Son Hing, L. (2015). Gender inequalities in the workplace: The effects of organizational structures, processes, practices, and decision makers' sexism. Frontiers in Psychology, 6, 1400. https://doi.org/10.3389/ fpsyg.2015.01400

Ternovszky, F. (2013). NÖ! a profit-Nöi Eröforrás Menedzsment. Wolters Kluwer.

Tsui, A. S., Egan, T. D., \& O’Reilly, C. A. (1992). Being different: Relational demography and organizational attachment. Administrative Science Quarterly, 37(4), 549-579. https://doi. org/10.2307/2393472

\section{APPENDIX}

Table 1. Interview subject details

\begin{tabular}{|l|l|l|l|l|}
\hline Interview subject & Gender & Age & \multicolumn{1}{|c|}{ Geographic coverage } & \multicolumn{1}{|c|}{ Role } \\
\hline Subject-1. & Female & 47 & Central Eastern Europe & Head of Human Resources \\
\hline Subject -2. & Female & 46 & France & Head of Human Resources \\
\hline Subject -3. & Male & 40 & Central Europe & Recruitment and Selection Head \\
\hline Subject -4. & Male & 39 & Hungary & Recruitment Head \\
\hline Subject -5. & Female & 39 & Spain & Senior HR Partner \\
\hline Subject -6. & Female & 34 & United Kingdom & University Relations Manager \\
\hline Subject -7. & Female & 28 & Romania & Recruiter \\
\hline Subject -8. & Female & 26 & Poland & Recruiter \\
\hline Subject -9. & Female & 32 & Poland & HR Business Partner \\
\hline Subject -10. & Female & 28 & Italy & HR Generalist \\
\hline Subject -11. & Female & 38 & Western Europe & Head of Senior Recruitment \\
\hline Subject -12. & Male & 53 & Central Eastern Europe & CEO \\
\hline Subject -13. & Male & 59 & Europe & CEO \\
\hline Subject -14. & Male & 45 & Hungary & CEO \\
\hline Subject -15. & Female & 44 & Poland & Head of HR \\
\hline Subject -16. & Female & 48 & United Kingdom & Head of HR \\
\hline Subject -17. & Male & 35 & Germany & Head of HR \\
\hline Subject -18. & Female & 36 & Hungary and Poland & Head of Campus Recruitment \\
\hline Subject -19. & Female & 38 & Czech Republic & Head of HR \\
\hline
\end{tabular}

